\title{
The Research about Subject Knowledge of Mathematics Educational Postgraduates
}

\author{
Li Sanping \\ School of Mathematics and information Science, Shaanxi \\ Normal University \\ Xian 710119 China
}

\author{
Guo Mengmin \\ Foreign Language School Attached to Guangxi Normal \\ University \\ Guilin 541004 China
}

\author{
Li Xinyi \\ School of Mathematics and information Science, Shaanxi Normal University, \\ Xian 710119 China
}

\begin{abstract}
The pre-service training of mathematics teachers is the beginning of the mathematics teacher professionalization, and the profound and solid foundation of mathematics discipline is the basic requirement of the professionalization of mathematics teachers. Thus, it is of vital importance for mathematics teachers to master enough mathematics subject knowledge in pre-service education. The present study examined mathematics subject knowledge of $\mathbf{1 2}$ full-time and $\mathbf{1 1}$ part-time master students in mathematics education. However, results show that some master students do not have a systematic and in-depth grasp of mathematics subject knowledge. Therefore, in the pre-service training stage of mathematics teachers, master students should attach great importance to the continuous development of their own mathematics subject knowledge subjectively, and at the same time, normal colleges should emphasize the fundamental position of mathematics professionalization while paying attention to the educational professionalization of students in normal college.
\end{abstract}

Keyword-mathematics teacher professionalization; mathematics subject knowledge; mathematics education master

\section{INTRODUCTION}

In the 1960s, the concept of teacher professionalization proposed in education research from Occident gradually became an important concept of guiding teacher education around the world. As the maturity of the related theory of teacher professionalization and the accumulation of practical experience, China also reached a consensus on strengthening teacher professionalization in the end of the 20th century. In 1998, the international symposium on normal education facing the 21 st century explicitly pointed out that the current teacher education reform is the core of teacher professionalization problem. It also added that training teacher professional level become the aim of international teacher education reform. Teacher professionalization is not only the need of teacher reform in China, but also the need of new curriculum reform and normal education development law [1].

In the aspect of mathematics education, mathematics teacher professionalization has been a particular concern by mathematics teacher education, and also has become the core issue of the world mathematics teacher education reform. Relevant studies show that in various countries the ranking of mathematics teachers' expertise is basically the same as that of students' math transcript in TIMSS (2007) [2].This intuitively reveals that mathematics teachers have a profound impact on students' mathematics learning and even mathematics education in various countries and indirectly explains the importance of mathematics teacher professionalization. The Specialization of mathematics teachers composes mathematics specialized, professional education and professional spirit [3]. In addition, the mathematical knowledge, mathematical ability and mathematics literacy build into mathematics professional structure. Education professional structure includes education discipline knowledge, scientific knowledge, general teaching ability and mathematics teaching ability.

The key of the professionalization of mathematics teachers is to coordinate and deal with the relationship between the mathematics professionalization and education professionalization, which has always been a hot issue about which one is more important of academic and educability in mathematics teacher education. As the approach or strategy of mathematics teacher professionalization must rely on mathematics, only study and master mathematics can we study mathematics education, mathematical thinking, mathematical methodology, mathematical philosophy, mathematics history and so on. [4]Since the pre-service training of mathematics teachers is the beginning of mathematics teachers' professionalization, [5] to some extent, the study of pre-service mathematics teacher about their mastery of subject knowledge is helpful to reflect the present professional developmental condition of them. There are some relevant studies indicated that $[6,7,8]$ despite the systematic learning at the undergraduate level, most pre-service mathematics teachers still do not have a deep and specific grasp of professional knowledge, and some may only stay at the basic understanding level.

Then, how is the level of mathematics education master in mathematics subject knowledge? Is the base of these mathematics teachers in professional subject knowledge solid enough? For this, we have conducted a small scale of survey on the mathematics education master students by selecting a medium difficulty algebra question about solving equations to find out the parameter range, in order to understand the actual situation of their mathematics subject knowledge. 


\section{METHOD}

\section{A. Participants}

12 full-time 2015 master students and 11 part-time 2014 master students in mathematics education from a normal university in Shaanxi province participated in the present study. The former has been systematically studied for four years as an undergraduate, while the latter has at least three-year teaching experience. To some degree, the selection of these two types of students as survey objects is conducive to a more comprehensive understanding of the mathematical subject knowledge level of master students in mathematics education.

\section{B. Procedure}

The test was administered during the period of their professional course among 23 participants, which resulted in $100 \%$ sample return. Collectively, the participants were given 15 minutes to complete the test. As this test also served as the usual-time mark of this professional course at the same time, during the test period the supervision strictly carried out accordance with the examination requirements, and the questionnaire efficiency achieves $100 \%$.

\section{Material}

In this survey we used the following test questions:

Analyze whether the solution of the following problem is correct or not? Explain why. If not, please give the correct solution.

Question: What's the value of $\mathrm{k}$ if the equations:

$$
\left\{\begin{array}{c}
y=x^{2}+k \\
x^{2}+y^{2}=2
\end{array}\right.
$$

have four sets ofreal solutions?

Solution: Change the form of equations into:

$$
2 y^{2}+y-(k+2)=0 \cdots \cdots \cdots(1)
$$

The formula has two different real roots

$$
\begin{aligned}
& \stackrel{\mathrm{B}}{\Leftrightarrow} \Delta=1+8(k+2)>0 \stackrel{\mathrm{D}}{\Leftrightarrow} \quad k>-\frac{17}{8} . \\
& \text { So, the answer to the question is: } k \in\left(-\frac{17}{8},+\infty\right) .
\end{aligned}
$$

\section{Scoring}

The solutions given by the respondents are marked according to the scoring points (marked by two reviewers in turn and arbitrated by the third reviewer if there is any difference in the scoring values). After that, analyzing the scores of all respondents with SPSS data analysis software (the full score is 10 points).

\section{RESULTS AND DISCUSSIONS}

\section{A. The judgment and corresponding reasons of respondents}

In the aspect of judging whether the solution to the problem is correct or not, all the respondents were able to correctly judge the given method is wrong. However, when stating the reason, only $58.33 \%$ of them found the essential cause of the wrong solution, that is because the range of the value $\mathrm{k}$ was be ignored. (included an answer for lack of another critical point of the value $\mathrm{k}$ ).This suggests that still $40 \%$ of respondents had not solid foundation of discipline professional knowledge, which caused the unclear understanding of the solution.

From the detail data in Figure 1, we can see that part-time master students' answer was much better than full-time master students. Among the full-time mathematics education master students, more than half failed to make the correct explanation and some even thought that equations was be converted into equation(1) without making the equation true. To some extent, it reflects the relative weak foundation of mathematics knowledge and lack of discrimination ability to specific problems.

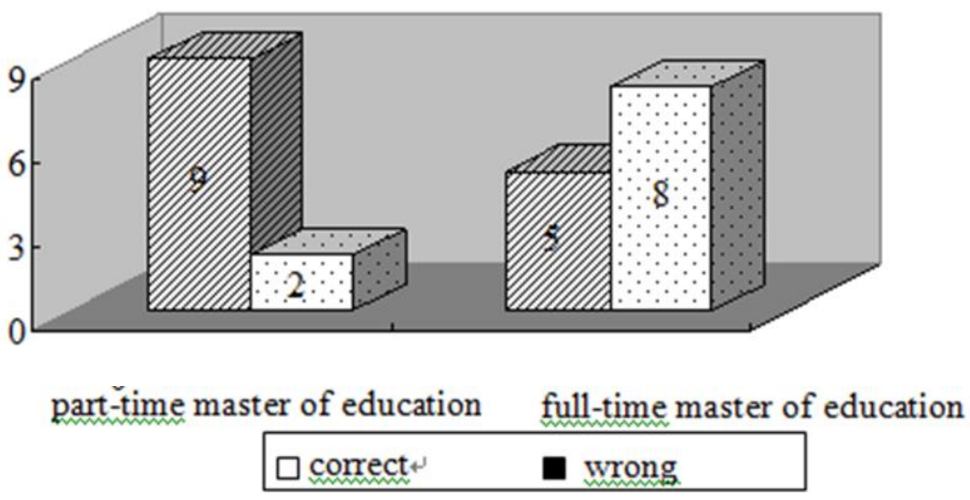

Fig. 1 The number of part-time and full-time master students whose answer is correct or not.

\section{$B$. The analysis of the solutions given by respondents}

After scoring and analyzing the data, the results are showed in table 1 . The average score of full-time master students was slightly higher, but the difference of the scores was more obvious. The score of part-time master students was more concentrated, but the average value was slight lower. In general, the average score of the respondents' solutions was less than half of the full score and the answers were not ideal. 


\begin{tabular}{lllllll}
\hline Type & $\mathrm{N}$ & Min. & Median & Max. & Mean & SD \\
\hline Part-time master of education & 11 & 4 & 4.00 & 6 & 4.18 & .603 \\
Full-time master of education & 13 & 2 & 4.00 & 10 & 4.69 & 2.780 \\
Total & 24 & 2 & 4.00 & 10 & 4.46 & 2.064
\end{tabular}

After classifying and analyzing the solutions of the problem, we found that 13 respondents, using the method of 'The combination of shape and number', changed four groups of real solution into four points of intersection between parabola and ellipse. However only one person found equivalent algebraic expressions and solved the parameter value range correctly, while the rest simply just saw the critical condition $(k<-1)$ so that either they ignored the limits of the other critical situation or solved incorrectly the other critical state by the formula: ' $|\sqrt{-k}|<\sqrt{2}$ '.

Eleven respondents used algebraic method. Seven reorganized the original equations as a quartic equation with the independent variable $\mathrm{x}$, but in the process of changing variable and decreasing degree of the equation, only two people noticed the value range of new variable $\mathrm{x}$ was greater than zero to ensure equations have four real solution. And only one of the two correctly solved the parameter range by two concealed condition (discriminant is greater than zero and two expressions of roots are greater than zero). The remaining 4 people were still discussed on the mono quadratic equation with the independent variable y. Although two of them found the value range of variable $y$ is limited, they failed to solve the range of parameter correctly.

The analysis of the results reflected that the respondents' mathematics subject knowledge was at a lower level. They failed to analyze and solve the problem from high viewpoints, and even unable to use the relevant knowledge they had studied in the middle school (the distribution of roots of mono quadratic equation). Most of the respondents' neglected the key points of solutions, which revealed their weakness in mathematics subject knowledge and deficits in comprehensive application ability of mathematics knowledge.

\section{CONCLUSIONS AND IMPLICATIONS}

The finding showed that although most of the respondents acquired the basic knowledge, their subject knowledge was not systematic and in-depth. In addition, generally they had difficulties in using related knowledge or skills to solve the specific problem and ignoring the critical knowledge. Therefore, the conservative statement we can make this moment is that mathematics education master students did not pay enough attention to professional knowledge in the learning process, which leads to their weak knowledge base.

Admittedly, as far as mathematics education is concerned, mastering abundant knowledge of mathematics subject knowledge may not effectively promote the teachers' professional development [9], but without a solid foundation of subject knowledge, mathematics teacher professionalization will not be able to play a role on it. Mathematics professionalization is a sign that mathematics teachers are different from teachers of other subjects. Deep and solid mathematics subject knowledge is the basic requirement of mathematics teacher professionalization.

As ontological knowledge, mathematics subject knowledge is the first thing that every professional mathematics teacher must grasp and master. Only with profound and broad mathematics knowledge, it is possible to efficiently and calmly engage in mathematics educational process and therefore lead students to go further in mathematics learning.

Besides mathematical teaching materials, middle school mathematics teachers should also grasp the mathematics history, mathematics applications and so on. So far, they can understand the mainstream trend of modern mathematics development, clearly recognize the inner link between elementary mathematics and higher mathematics, and then master the theory background and structure of middle school mathematics, so that they can think and explore the middle school mathematics problem from the high viewpoints [10]. Indeed, it is very necessary for mathematics teachers to learn enough mathematics science knowledge in pre-service education [3].

We believe that, first of all, normal university students should attach great importance to mathematics subject knowledge subjectively, establish correct concept of subject content knowledge and carry out continuous learning and in-depth exploration of subject professional knowledge throughout the whole learning career. On the one hand, only by reserving a large amount of academic form of mathematics knowledge can we better promote the transformation of mathematics knowledge from academic to educational form. On the other hand, it can avoid the tendency of taking mathematics away in math education better.

Secondly, regarding teachers' mathematical knowledge as the beginning is the most direct and effective way to generate and develop the MPCK of mathematics teachers [11], which can promote the professional development of mathematics teachers better and avoid the situation of limited professional development caused by insufficient academic skills in teaching career. In addition the smooth development of individual can effectively promote the professionalization of group mathematics teachers.

Finally, in the pre-service training stage of mathematics teachers in normal universities, while paying attention to the professionalization of teachers and students, the basic position of mathematics professionalization should be emphasized, so as to promote the professionalization of pre-service mathematics teachers much better. In terms of instructional 
hour, mathematics subject knowledge should have priority. Mathematics subject knowledge, humanities knowledge and general pedagogical knowledge should be supplemented [10]. Additionally, curriculum set and structure must strengthen the connection with middle school mathematics.

This study gives rise to important implications for part-time mathematics teacher training process. We should balance the relationship between education professional and mathematics professional in order to effectively promote mathematics teachers professionalization. Not only should we realize the importance of education discipline foundation, but also need to return to it, pay attention to its development as well as enhancing the profound study of mathematics subject knowledge. Just as the famous scholar professor Zheng Yuxin said, we should clearly oppose the one-sided emphasis on the attribute of mathematics education or mathematics and pay more attention to the dialectical relationship between the two of them [12].

\section{ACKNOWLEDGEMENT}

Thanks to the help of graduate program of Shaanxi Normal University (NO.Gerp-19-40) in this research.

\section{REFERENCES}

[1] Chen Xiaoli. Teacher specialization: a watershed to improve teachers' professional taste $[\mathrm{J}]$. Theory and Practice of Education,2003(2):49-53.

[2] Mullis I. V.S., Martin M. O., \&Foy P.. TIMSS 2007 international mathematics report: findings from IEA's trends in international mathematics and science study at the fourth and eighth grades[M]. Chestnut Hill: TIMSS \& PIRIS International Study Center, Boston College, 2008: 243-264.

[3] Wang Zixing. On the connotation of mathematics teacher specialization [J]. Journal of mathematics education,2002(4):63-67.

[4] Zeng zheng, Yang zhi. Some thoughts on "mathematics teacher professionalization" [J]. Journal of mathematics education,2003(1):50-50.

[5] Ye Lijun. Specialization of mathematics teachers and curriculum reform of undergraduate mathematics education $[\mathrm{J}]$. Journal of mathematics education,2002(4):68-71.

[6] Wu jun, liu jun. Investigation and analysis on professional development of pre-service mathematics teachers [J]. China adult education,2009(14):88-89.

[7] You-chu huang. Research on the professionalization degree of quasi-mathematics teachers $[\mathrm{J}]$. Journal of mathematics education,2011(6):29-31.

[8] Mengmin Guo, Sanping Li. Discussion of Normal University Students' SMK and the Development of MPCK [C]. Advances in Intelligent Systems Research--Education, Management and Computer Science (Part 8) , Paris: Atlantis Press, 2015(129), 1109-1113.

[9] Chen ziqiang, hu dianshun, he sui. Review of current MPCK research in China [J]. Journal of mathematics education,2012(5):15-18.

[10] Wang yanwen, cui hong. Specialization and curriculum reform of mathematics teachers [J]. Journal of mathematics education,2003(2):78-82.

[11] TongLi. A new perspective on the professional development of mathematics teachers -- mathematics teaching content knowledge (MPCK) [J]. Journal of mathematics education,2010(2):23-27.

[12] Zheng Yuxin. 6 key words for the professional growth of mathematics teachers [J]. Teaching reference of mathematics school middle .2015(4):8-10. 